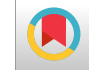

\title{
Breastfeeding, Serum Level of Hemoglobin and Ferritin Associated with the Risk of Asthma in Children: A Case-Control Study
}

\author{
Afsaneh Sadeghian ${ }^{1}$, Fateme Moghaddam ${ }^{2}$, Khatereh Babakhani ${ }^{3}$, Saba Shakarami ${ }^{4}$, Pouneh \\ Zolfaghari ${ }^{5}$, Mohammad Bagher Sohrabi ${ }^{6}$ and Mostafa Dianatinasab ${ }^{6,}$ \\ ${ }^{1}$ Clinical Research Development Unit, Imam Hossein Hospital, Shahroud University of Medical Sciences, Shahroud, Iran \\ ${ }^{2}$ Bahar Center for Education, Research and Treatment, Shahroud University of Medical Sciences, Shahroud, Iran \\ ${ }^{3}$ Department of Nutrition, Science and Research Branch, Islamic Azad University, Tehran, Iran \\ ${ }^{4}$ School of Health, Ilam University of Medical Sciences, Ilam, Iran \\ ${ }^{5}$ Department of Pediatric, School of Medicine, Shahroud University of Medical Sciences, Shahroud, Iran \\ ${ }^{6}$ Department of Epidemiology, Center for Health Related Social and Behavioral Sciences Research, Shahroud University of Medical Sciences, Shahroud, Iran \\ "Corresponding author: Department of Epidemiology, Center for Health Related Social and Behavioral Sciences Research, Shahroud University of Medical Sciences, Shahroud, \\ Iran. Email: dianatinasab@sums.ac.ir
}

Received 2019 April 30; Revised 2019 December 22; Accepted 2020 January 15

\begin{abstract}
Background: During recent decades, there has been a dramatic increase in the prevalence of asthma in children. There is low-grade quality evidence that breastfeeding and anemia are associated with a reduced risk of asthma in children up to 5 years of age.

Objectives: Regarding the high prevalence of anemia and asthma in Iranian children, we aimed to evaluate the risk factors for asthma in children.

Methods: The present case-control study examined 110 children ( 55 cases and 55 controls) aged 3 to 12, admitted to Shahroud educational hospitals from March 2017 to February 2018. The children diagnosed based on the Global Initiative for Asthma criteria, by a specialist physician, were selected as the case group and those admitted to other hospital wards for diseases (such as orthopedic and nephrology), other than respiratory problems were selected as the control group. Multivariable logistic regression was used to find asthma risk factors. $\mathrm{P}<0.05$ was considered statistically significant.

Results: Of 110 children, 63 (57.3\%) were boy and mean ( \pm standard deviation (SD)) age of the participants was 7.23 ( \pm 4.17) years and mean weight was 29.6 ( \pm 21.6$) \mathrm{kg}$. Most of the children (76.4\%) were fed by breast milk during infancy. Mean $( \pm$ SD) Hb in the case group was $10.4( \pm 2.5) \mathrm{g} / \mathrm{dL}$ and in the control group was $11.5( \pm 2.3) \mathrm{g} / \mathrm{dL}(\mathrm{P}=0.01)$. The prevalence of anemia was $72.7 \%$ and $50.9 \%$ in the case and control group, respectively $(\mathrm{P}<0.001)$. After controlling for potential confounders, breastfeeding (OR breast milk only vs. formula only $=2.23, \mathrm{P}=0.01)$, serum level of hemoglobin $(\mathrm{OR}=0.13, \mathrm{P}=0.002)$ and ferritin $(\mathrm{OR}=0.32, \mathrm{P}=0.04)$ were significantly associated with the risk of asthma.

Conclusions: Our study found the role of low duration of breastfeeding and ferritin deficiency as a risk factor for development of asthma in children. This finding emphasizes that iron supplementation along with breastfeeding in childhood may prevent asthma and hence reduce the children's mortality and morbidity rates associated with asthma.
\end{abstract}

Keywords: Asthma, Breastfeeding, Ferritin Levels, Iron Deficiency Anemia, Children

\section{Background}

Asthma is a chronic inflammatory disease with reversible airway obstruction, which causes wheezing, breathlessness, chest tightness, and coughs (1). It is a major cause of hospital admission and asthmatic attacks that can be associated with mortality (2). In addition, it is associated with several comorbidities that increase the risk of disease exacerbation (3). Asthma involves $4.3 \%$ of the world population, while the average annual asthma prevalence is higher in children than adults (4). Despite different prevalence rates reported, according to different definitions, the prevalence of asthma is apparently higher in Iran than in other countries, especially in children (5). The high prevalence and the increasing trend in the past few decades in Iran, necessitates paying more attention to this disease in the country (6).

Although various pathophysiologies have been suggested for the disease, including the role of allergy, inflammation, and genetic mutations, the definite etiology of asthma is unclear (7). Generally, asthma is considered a multifactorial disease and various genetic and environmental factors are suggested to play a role in its incidence, 
attacks, and exacerbations $(8,9)$. For example, it has been suggested that a family history of asthma and allergies significantly influences the risk of asthma in children $(7,8)$. In addition, to gastroesophageal reflux, air pollution, emotional stress, and viruses, nutrients, such as vitamins (C and B), and minerals (like magnesium, zinc, and selenium) have been proposed to be involved in the pathophysiology of asthma (10). It has been suggested that, low hemoglobin $(\mathrm{Hb})$ level is a risk factor for respiratory tract infections (RTI) $(11,12)$ and iron supplementation has been shown to reduce the mortality of RTI (13). Also, anemia is associated with the inflammation in chronic obstructive pulmonary disease (COPD) and affects patients' mortality and quality of their lives $(14,15)$. Nevertheless, there is little evidence on the association between asthma and anemia (16). In addition, the available literature reported conflicting results: although animal models suggest that systemic administration of iron could suppress airway manifestations of allergic asthma (17) and exhaled concentration of asthmatic patients was lower than the healthy controls (18), another case-control study indicated no difference in serum iron level of asthmatic patients, compared with healthy subjects (19).

\section{Objectives}

Because of the controversies in the results of studies about the association between asthma and anemia and the high disease burden of asthma (20), we aimed to investigate the association between breastfeeding, anemia and sociodemographic factors with the risk of asthma in Iranian children. In case a positive association is found, a step can be taken toward the reduction of asthma-related morbidity/mortality by iron supplementation.

\section{Methods}

\subsection{Study Design}

The present case-control study examined 110 children, admitted to Shahroud educational hospitals from March 2017 to February 2018. The protocol of the study was approved by the Ethics Committee of Shahroud University of Medical Sciences (Code: IR.SHMU.REC.1395.86). Before patient selection, the design and objectives of the study were explained to the parents and written informed consent was obtained from them for participation of their children in the study. All data were recorded and analyzed without names and confidentiality of the data, as well as other ethical issues, were met throughout the study, according to Helsinki's Declaration on human studies.
Sample size was priori calculated in order to detect an increase in the risk of asthma among those with a history of formula feeding as small as 2.4 times (odds ratio $=2.4$ ) of the risk for those with no breastfeeding. The alpha (a) value and power were set at 0.05 (two sided) and $80 \%$ respectively. Accordingly, the sample size of this study was calculated at 55 children in each group, according to the study by Ramakrishnan et. al., study (16).

The inclusion criteria for the case group consisted of children, below the age of 12 year, who were admitted to the respiratory ward of the selected hospitals with the diagnosis of asthma, based on Global Initiative for Asthma (GINA) criteria (21) by a specialist physician, whose parents gave consent for participation of their children in the study. All patients who had stable vital signs were recruited. The exclusion criteria consisted of other allergies, sinusitis, cystic fibrosis, immunodeficiency, congenital/chronic pulmonary diseases, congenital malformation of the chest wall, severe systemic disease, or any patient requiring medical interventions or surgical procedure, resulting in blood loss.

The inclusion criteria for the control group consisted of children, aged $<12$ years, with stable vital signs, who were admitted to different wards of the same hospitals for diseases (like orthopedic, nephrologic, etc.), other than respiratory problems. The exclusion criteria of the control group consisted of all the criteria mentioned for the case group, in addition to no respiratory problems. The control group was matched for sex and age with the case group.

The demographic characteristics of the study participants (including age, sex, height, and weight, as well as the method of feeding during infancy) were recorded and one blood sample $(5 \mathrm{cc}$ ) was taken from each child in the morning, and serum levels of $\mathrm{Hb}$, ferritin, and iron were measured. Hemoglobin (indexed in the CBC test) was measured in the laboratory by Cell Counter set (Celena D1 Abbott; ABOOT Cell Dyn 3700, USA). Ferritin was measured in the laboratory using ECLIA (electrochemiluminescence immunoassay analyzer) method (Ultra measurement method; Cell Counter, SYSMEX KX21N, Japan) and the Iron serum was measured in the laboratory using a photometric method by Ferrozine method (a Transformation method; Ferrozine method, Pishtazteb diagnostics Kit, Iran).

Body mass index (BMI) was calculated by the division of weight (in $\mathrm{kg}$ ) by the squared height (in meters) and reported as $\mathrm{kg} / \mathrm{m}^{2}$. According to the standard protocols, anemia was considered $\mathrm{Hb}<10.9 \mathrm{~g} / \mathrm{dL}$ for the ages $4-6$ years, $<11.9 \mathrm{~g} / \mathrm{dL}$ for the ages $5-12$ years. Also, Anemia was considered ferritin $<10 \mathrm{ng} / \mathrm{mL}$ for the ages $4-6$ years, $<15 \mathrm{ng} / \mathrm{mL}$ for the ages 5 - 11 years, and $<20 \mathrm{ng} / \mathrm{mL}$ for the ages $11-14$ years and higher, below the level according to the age (22). 
The collected data were compared between the groups according to the diagnosis of anemia.

\subsection{Statistical Analysis}

The data were inserted into an excel sheet. For reporting the results, quantitative variables were presented as mean \pm standard deviation (SD) and categorical variables by frequency (percentage). For the comparison of continuous variables between the groups, $t$-test was used and for that of categorical variables, chi-square test was used. To find risk factors for asthma, and control the role of possible role of confounder variables, and to measure the adjusted association of each independent variable with the risk of asthma, a multivariable logistic regression model was fitted to the data using stepwise variable selection strategy. The modeling procedure was started after collinearity between the independent variables was tested using variance inflation factor index (VIF).

For the statistical analysis, the statistical software IBM SPSS Statistics for Windows version 16.0 (IBM Corp., the United States) was used. P values $\leq 0.05$ were considered statistically significant.

\section{Results}

Of 110 participants, 55 (50\%) were assessed in the case group and 55 (55\%) in the control group. Of the total participants, 63 (57.3\%) were boys and the rest were girls and the sex distribution of the participants was not different between the groups $(\mathrm{P}>0.05)$ (Table 1$)$.

Mean $( \pm S D)$ age of the participants was $7.23( \pm 4.17)$ years with a range of $3-12$ years. Categorizing the age to $<$ $4,4-7,8-11$, and $>11$ years showed that more than half of the patients (51.8\%) were in the age category of $4-7$ years.

Mean ( \pm SD) weight of the case group was $28.9( \pm 24.8)$ $\mathrm{kg}$ with a range of 9.5 to $45.5 \mathrm{~kg}$ and that of the control group was $30.2 \pm 23.5 \mathrm{~kg}$ with a range of 10.5 to $47.5 \mathrm{~kg}$ without a significant difference between two groups $(\mathrm{P}=$ 0.085). Mean ( \pm SD) height of the case group was 118.6 ( \pm 21.7) $\mathrm{cm}$ with a range of 98.5 to $155.5 \mathrm{~cm}$ and that of the control group was $120.1( \pm 22.6) \mathrm{cm}$ with a range of 99.5 to 157.5 $\mathrm{cm}$ without significant difference $(\mathrm{P}=0.115)$. Mean $( \pm \mathrm{SD})$ BMI of the case group was $19.88( \pm 6.18) \mathrm{kg} / \mathrm{m}^{2}$ with a range of 17.7 to $26.9 \mathrm{~kg} / \mathrm{m}^{2}$ and that of the control group was 19.72 $\pm 6.33 \mathrm{~kg} / \mathrm{m}^{2}$ with a range of 18.2 to $27.3 \mathrm{~kg} / \mathrm{m}^{2}$ without significant difference $(\mathrm{P}=0.103)$.

Most of the participants (65.5\%) were the results of normal vaginal delivery, most (76.4\%) were fed by breast milk during infancy, and most lived in urban areas (77.3\%). There was a significant difference between the two groups in the distribution of feeding method during infancy $(\mathrm{P}<0.05)$, while there was none in terms of delivery method and living place $(\mathrm{P}>0.05)$. The frequency of all demographic variables according to the study groups are shown in Table 1.

Mean $( \pm$ SD) Hb in the case group was $10.4( \pm 2.5) \mathrm{g} / \mathrm{dL}$ and in the control group was $11.5( \pm 2.3) \mathrm{g} / \mathrm{dL}(\mathrm{P}=0.01)$ (Table 2). Mean $( \pm$ SD) ferritin level was $26.6( \pm 3.8) \mathrm{g} / \mathrm{dL}$ with a significant difference between the groups and was significantly higher in the control group $(\mathrm{P}<0.001)$. The results of the laboratory measurements are shown in Table 2.

The prevalence of anemia (based on hemoglobin) was $61.8 \%$ in all participants $(72.7 \%$ in the case group and $50.9 \%$ in the control group) $(\mathrm{P}<0.001)$ (Table 3$)$. The prevalence of anemia, based on ferritin level, is also shown in Table 3. Also, the results showed a significant association between the child's sex $(\mathrm{P}=0.033)$ and the type of infant feeding ( $\mathrm{P}$ $=0.017$ ) with anemia.

As shown in Table 4, after controlling potential confounders, multivariable logistic regression shows that breastfeeding (OR breast milk only vs. formula only $=2.23$, $\mathrm{P}=0.01)$, serum level of hemoglobin $(\mathrm{OR}=0.13, \mathrm{P}=0.002)$ and ferritin $(\mathrm{OR}=0.32, \mathrm{P}=0.04)$ were significantly associated with the risk of asthma. According to the results of multivariable logistic regression, we found no statistically significant association between sex, delivery method, and residency or living place and the risk of asthma ( $\mathrm{P}$ for all $>$ 0.05).

\section{Discussion}

Our study supported the hypothesis that low duration of breastfeeding and ferritin deficiency may play a significant role in development of asthma in children. The present study showed that the overall prevalence of anemia was about $62 \%$. This prevalence seems to be much higher than the global prevalence of anemia in children $(43 \%-47 \%)(23,24)$. A recent Iranian report indicated the prevalence of anemia in hospitalized children at 40\% (25), which is lower than the present study. Overall estimates of anemia have been reported at $10.8 \%$ in children aged 2 - 6 years, and 15\% in children aged 7 - 12 years (26), and about $14 \%$ in the population younger than 18 (27), which is much less than the present study. In the present study, the prevalence of anemia in the control group was about 51\%, which is again higher than the previous reports, as mentioned above. This could be due to the significant difference in the prevalence of anemia in different provinces of the country (28). As suggested, anemia depends on various factors, such as the place of living (rural or urban) (29), socioeconomic factors $(30,31)$, and breastfeeding (32). Although one of the factors that may justify the high prevalence of anemia in the present study could be the fact that most participants lived in urban areas, the prevalence of 


\begin{tabular}{|c|c|c|c|c|}
\hline Variables & Case Group, No. (\%) & Control Group, No. (\%) & Total & PValue $^{\mathrm{a}}$ \\
\hline Sex & & & & 0.085 \\
\hline Girl & $31(56.4)$ & $32(58.2)$ & $63(57.3)$ & \\
\hline Boy & $24(43.6)$ & $23(41.8)$ & $47(42.7)$ & \\
\hline Age category, y & & & & 0.012 \\
\hline$<4$ & $6(10.9)$ & $5(21.7)$ & $11(10)$ & \\
\hline $4-7$ & $27(49.1)$ & $30(54.5)$ & $57(51.8)$ & \\
\hline $8-11$ & $13(23.6)$ & $13(23.6)$ & $24(21.8)$ & \\
\hline$>11$ & $9(16.4)$ & $9(16.4)$ & $18(16.4)$ & \\
\hline Family history of asthma & & & & 0.054 \\
\hline No & $42(76.36 \%)$ & $45(81.81 \%)$ & & \\
\hline Yes & $13(23.64 \%)$ & $10(18.19 \%)$ & & \\
\hline Delivery method & & & & 0.108 \\
\hline Normal vaginal delivery & $37(67.3)$ & $35(63.6)$ & $72(65.5)$ & \\
\hline Cesarean delivery & $18(32.7)$ & $20(36.4)$ & $38(34.5)$ & \\
\hline Feeding method & & & & 0.03 \\
\hline Breast milk only & $39(70.9)$ & $45(81.8)$ & $84(76.4)$ & \\
\hline Formula only & $5(9.1)$ & $3(5.5)$ & $8(7.3)$ & \\
\hline Breast milk and formula & $11(20)$ & $7(12.7)$ & $18(16.4)$ & \\
\hline Living place & & & & 0.124 \\
\hline Urban & $44(80)$ & $41(74.5)$ & $85(77.3)$ & \\
\hline Rural & $11(20)$ & $14(25.5)$ & $25(22.7)$ & \\
\hline
\end{tabular}

${ }^{\mathrm{a}}$ The results of chi-square test at significance level of 0.05 .

\begin{tabular}{|c|c|c|c|c|}
\hline & Mean \pm SD & Minimum & Maximum & PValue $^{\mathbf{a}}$ \\
\hline Hemoglobin, g/dL & & & & 0.015 \\
\hline Case group & $10.4 \pm 2.5$ & 8.5 & 12.5 & \\
\hline Control group & $11.5 \pm 2.3$ & 8.8 & 12.0 & \\
\hline Ferritin, $\mathbf{g} / \mathbf{d L}$ & & & & $<0.001$ \\
\hline Case group & $24.9 \pm 17.5$ & 6.0 & 39 & \\
\hline Control group & $28.1 \pm 19.3$ & 11.0 & 45.0 & \\
\hline
\end{tabular}

${ }^{\mathrm{a}}$ The results of $t$-test at significance level of 0.05 .

\begin{tabular}{|c|c|c|c|c|}
\hline Variables & Case Group, No. (\%) & Control Group, No. (\%) & Total & PValue $^{\mathrm{a}}$ \\
\hline With anemia & $40(72.7)$ & $28(50.9)$ & $68(61.8)$ & \multirow{2}{*}{$<0.001$} \\
\hline Without anemia & $15(27.3)$ & $27(49.1)$ & $42(38.2)$ & \\
\hline With anemia & $24(43.6)$ & $15(27.3)$ & $39(35.5)$ & \multirow{2}{*}{0.023} \\
\hline Without anemia & $31(56.4)$ & $40(72.7)$ & $71(64.5)$ & \\
\hline
\end{tabular}

${ }^{\mathrm{a}}$ The results of chi-square test at significance level of 0.05 .

anemia cannot be compared easily among the studies, as each study population selected might have different socioeconomic status, use a specific nutrition, etc., resulting in different reported data. According to the results of the present study, children younger than 12 years hospitalized in Shahroud hospitals had a significantly high prevalence of anemia, which calls for the attention of policymakers to this issue in this province.

A few studies have suggested that a longer duration of breastfeeding can have protective effects against the de- 
Table 4. Adjusted Association Between the Study Variables and Risk of Asthma in Children Aged 3 - 12 Years Old.

\begin{tabular}{|c|c|c|c|}
\hline \multirow{2}{*}{ Variables } & \multicolumn{3}{|c|}{ Multivariable Logistic Regression Model } \\
\hline & OR & 95\% CI & PValue \\
\hline \multicolumn{4}{|l|}{ Breastfeeding } \\
\hline $\begin{array}{l}\text { Breast milk } \\
\text { only }\end{array}$ & $1^{\mathrm{a}}$ & - & - \\
\hline Formula only & 2.23 & $1.15,4.73$ & 0.01 \\
\hline \multicolumn{4}{|l|}{ Sex } \\
\hline Female & 1 & - & - \\
\hline Male & 2.06 & $0.79,4.32$ & 0.09 \\
\hline \multicolumn{4}{|l|}{ Delivery method } \\
\hline $\begin{array}{l}\text { Normal } \\
\text { vaginal } \\
\text { delivery }\end{array}$ & 1 & - & - \\
\hline $\begin{array}{l}\text { Cesarean } \\
\text { delivery }\end{array}$ & 1.21 & $0.48,3.28$ & 0.06 \\
\hline \multicolumn{4}{|l|}{ Residency } \\
\hline Urban & 1 & - & - \\
\hline Rural & 1.07 & $0.63,3.25$ & 0.23 \\
\hline $\begin{array}{l}\text { Serum level of } \\
\text { hemoglobin }^{b}\end{array}$ & 0.13 & $0.04,0.34$ & 0.002 \\
\hline $\begin{array}{l}\text { Serum level of } \\
\text { ferritin }^{b}\end{array}$ & 0.32 & $0.09,0.67$ & 0.04 \\
\hline \multicolumn{4}{|l|}{$\begin{array}{l}\text { Family history of } \\
\text { asthma }\end{array}$} \\
\hline No & 1 & - & - \\
\hline Yes & 1.18 & $0.83-2.79$ & 0.16 \\
\hline
\end{tabular}

Abbreviations: 95\% CI, 95\% confidence interval; OR, odds ratios

${ }^{a}$ Reference category

${ }^{\mathrm{b}}$ The variable was interred in to the medal as a continuous variable.

velopment of asthma in children. A national populationbased longitudinal survey of children and youth on a sample of 331,100 children revealed that there is a doseresponse effect with breastfeeding duration and asthma (33). Also, In line with our findings, results of a systematic review and meta-analysis of 42 articles on the association between breastfeeding and asthma and allergies shows that more duration of breastfeeding compare to less duration was associated with reduced risk of asthma for children aged 5 - 18 years, and this protection association was more significant in low/medium-income countries (34).

The comparison of 55 asthmatic children with 55 controls in the present study indicated a significantly higher prevalence of anemia and a lower mean serum level of $\mathrm{Hb}$. These results are in line with another case-control study on children, indicating a higher prevalence of anemia in the children with asthma than that of the matched control group. In this study, mean Hb levels was $10.58 \mathrm{~g} / \mathrm{dL}$ in the asthmatic group and 11.75 in the control group (35), which is very close to the mean Hb levels in the children of our study (10.4 $\mathrm{g} / \mathrm{dL}$ in the case group and $11.5 \mathrm{~g} / \mathrm{dL}$ in the control group). Also, in a prospective cohort study on 100 outpatient children aged 6 - 16 years, the results indicated a significantly higher prevalence of asthma in children with iron deficiency anemia and a positive correlation between $\mathrm{Hb}$ levels and pulmonary function parameters (FEV1, FVC, FEV1/FVC, and PEF) in this group (36), which is in line with the results of the present study. Further research has proven the role of mothers' anemia on the higher risk of asthma in their children, which indicates the significant association of anemia and asthma, not only in the patients but also in their next-generation (37), which is in line with the results of the present study, emphasizes the importance of treating anemia for prevention of asthma. This effect can be justified by the role of $\mathrm{Hb}$ in oxygen, carbon dioxide, and nitric oxide transport (38); thus, dysfunction of $\mathrm{Hb}$ by anemia may affect asthma by disturbing the oxygen pressure stability in tissues. The results of the present study emphasize the significance of paying more attention to anemia in Iranian children, especially in Shahroud, which along with severe anemia-associated complications and the disease burden (39); also, affects the prevalence of asthma.

Another important finding of the present study was significantly higher mean serum level of ferritin in the control group, compared with the asthmatic patients. Another study on women in the United States indicated that a higher serum level of ferritin was associated with decreased odds of asthma (40), which is in line with the results of the present study. In the study by Bener et al., ferritin was identified as a significant predictor of asthma after adjustment for other variables (35), which confirms the results of the present study. Eissa et al. also indicated a positive correlation between ferritin levels and pulmonary function parameters (FEV1, FVC, FEV1/FVC, and PEF) in children with iron deficiency anemia (36), which is consistent with the results of the present study. These studies, along with the results of the present study, indicate the significant role of iron in asthma. Considering the high prevalence of iron deficiency in Iranian children (41), and despite the efforts of health evolutionary plans, supplementation of iron seems an important measure to be considered by policymakers, which along with other benefits, may also reduce the prevalence of asthma.

Along with the strengths of the present study, it might be affected by several limitations. One of the main limitations of the present study was the case-control design of the study. In this study, the control group was matched with the case group in terms of age and the results showed significant difference between the groups in age distribu- 
tion. In addition, non-random sampling might affect the results. Lastly, data on some socio-economic status of the family, and history of respiratory tract infection or past history of atopy in early childhood were not available, which should be considered a limitation of this study.

Altogether, as the sample was selected from one province, the results of this study could not be generalized to all Iranian children. Future cohort or randomized clinical trials, with a larger sample size and selection of samples from different provinces, can add new findings to the results of the present study and provide researchers with a wider view toward this issue.

\subsection{Conclusions}

The results of the present study indicated that breastfeeding, serum level of hemoglobin and ferritin were significantly associated with the risk of asthma in children. We found that breastfeeding was the most important preventive factor for the risk of asthma. In addition, the results indicated a higher prevalence of anemia and lower Hb levels in children with asthma, compared with the control group, which shows the role of iron as a risk factor of asthma in children. This finding emphasizes the significant effect of some modifiable factors on the risk of asthma. Further studies on the effect of iron supplementation on reducing the asthmatic attacks, exacerbations, or symptoms are required.

\section{Acknowledgments}

The present study was supported by Shahroud University of Medical Sciences as a Medical Doctor(MD)Thesis. We hereby acknowledge the research deputy. Also, we would like to thank all parents of the participants.

\section{Footnotes}

Authors' Contribution: Study concept and design: Fateme Moghaddam and Afsaneh Sadeghian; analysis and interpretation of data: Fateme Moghaddam and Khatereh Babakhani; drafting of the manuscript: Pouneh Zolfaghari and Mostafa Dianatinasab; critical revision of the manuscript for important intellectual content: Mohammad Bagher Sohrabi and Mostafa Dianatinasab; statistical analysis: Afsaneh Sadeghian.

Conflict of Interests: The authors declared that they have no conflict of interest.

Ethical Approval: This study was approved by the Ethics Committee of Shahroud University of Medical Sciences (Code: IR.SHMU.REC.1395.86).

Funding/Support: The present study was financially supported by Shahroud University of Medical Sciences.
Informed Consent: Literate patients read and signed informed consent and verbal consent was obtained from illiterate patients.

\section{References}

1. Murdoch JR, Lloyd CM. Chronic inflammation and asthma. Mutat Res. 2010;690(1-2):24-39. doi: 10.1016/j.mrfmmm.2009.09.005. [PubMed: 19769993]. [PubMed Central: PMC2923754].

2. Bousquet J, Mantzouranis E, Cruz AA, Ait-Khaled N, Baena-Cagnani $\mathrm{CE}$, Bleecker ER, et al. Uniform definition of asthma severity, control, and exacerbations: Document presented for the World Health Organization Consultation on Severe Asthma. J Allergy Clin Immunol. 2010;126(5):926-38. doi: 10.1016/j.jaci.2010.07.019. [PubMed: 20926125].

3. Lisspers K, Janson C, Larsson K, Johansson G, Telg G, Thuresson $\mathrm{M}$, et al. Comorbidity, disease burden and mortality across age groups in a Swedish primary care asthma population: An epidemiological register study (PACEHR). Respir Med. 2018;136:15-20. doi: 10.1016/j.rmed.2018.01.020. [PubMed: 29501242].

4. Loftus PA, Wise SK. Epidemiology of asthma. Curr Opin Otolaryngol Head Neck Surg. 2016;24(3):245-9. doi: 10.1097/MOO.0000000000000262. [PubMed: 26977741].

5. Entezari A, Mehrabi Y, Varesvazirian M, Pourpak Z, Moin M. A systematic review of recent asthma symptom surveys in Iranian children. Chron Respir Dis. 2009;6(2):109-14. doi: 10.1177/1479972309103884. [PubMed: 19411572].

6. Ghaffari J,Aarabi M. The prevalence of pediatric asthma in the Islamic Republic of Iran: A systematic review and meta-analysis. J Pediatr Rev. 2013;1(1):2-11.

7. Kudo M, Ishigatsubo Y, Aoki I. Pathology of asthma. Front Microbiol. 2013;4:263. doi: 10.3389/fmicb.2013.00263. [PubMed: 24032029]. [PubMed Central: PMC3768124].

8. Bener A, Janahi IA, Sabbah A. Genetics and environmental risk factors associated with asthma in schoolchildren. Eur Ann Allergy Clin Immunol. 2005;37(5):163-8. [PubMed: 15984314].

9. Covar RA, Szefler SJ, Zeiger RS, Sorkness CA, Moss M, Mauger DT, et al. Factors associated with asthma exacerbations during a longterm clinical trial of controller medications in children. J Allergy Clin Immunol. 2008;122(4):741-747 e4. doi: 10.1016/j.jaci.2008.08.021. [PubMed: 19014765]. [PubMed Central: PMC3024439].

10. Miller AL. The etiologies, pathophysiology, and alternative/complementary treatment of asthma. Altern Med Rev. 2001;6(1):20-47. [PubMed: 11207455].

11. Hussain SQ, Ashraf M, Wani JG, Ahmed J. Low hemoglobin level a risk factor for acute lower respiratory tract infections (ALRTI) in children. J Clin Diagn Res. 2014;8(4):PC01-3. doi: 10.7860/JCDR/2014/8387.4268. [PubMed: 24959486]. [PubMed Central: PMC4064840].

12. Ramakrishnan K, Harish PS. Hemoglobin level as a risk factor for lower respiratory tract infections. Indian J Pediatr. 2006;73(10):881-3. doi: 10.1007/bf02859279. [PubMed: 17090898].

13. de Silva A, Atukorala S, Weerasinghe I, Ahluwalia N. Iron supplementation improves iron status and reduces morbidity in children with or without upper respiratory tract infections: A randomized controlled study in Colombo, Sri Lanka. Am J Clin Nutr. 2003;77(1):234-41. doi: 10.1093/ajcn/77.1.234. [PubMed: 12499347].

14. Yohannes AM, Ershler WB. Anemia in COPD: A systematic review of the prevalence, quality of life, and mortality. Respir Care. 2011;56(5):64452. doi: 10.4187/respcare.01002. [PubMed: 21276321].

15. John M, Hoernig S, Doehner W, Okonko DD, Witt C, Anker SD Anemia and inflammation in COPD. Chest. 2005;127(3):825-9. doi: 10.1378/chest.127.3.825. [PubMed: 15764763] 
16. Ramakrishnan K, Borade A. Anemia as a risk factor for childhood asthma. Lung India. 2010;27(2):51-3. doi: 10.4103/0970-2113.63605. [PubMed: 20616934]. [PubMed Central: PMC2893424].

17. Maazi H, Shirinbak S, Bloksma N, Nawijn MC, van Oosterhout AJ. Iron administration reduces airway hyperreactivity and eosinophilia in a mouse model of allergic asthma. Clin Exp Immunol. 2011;166(1):806. doi: 10.1111/j.1365-2249.2011.04448.x. [PubMed: 21910724]. [PubMed Central: PMC3193922].

18. Vlasic Z, Dodig S, Cepelak I, Topic RZ, Zivcic J, Nogalo B, et al. Iron and ferritin concentrations in exhaled breath condensate of children with asthma. J Asthma. 2009;46(1):81-5. doi: 10.1080/02770900802513007. [PubMed: 19191143].

19. Vural H, Uzun K, Uz E, Kocyigit A, Cigli A, Akyol O. Concentrations of copper, zinc and various elements in serum of patients with bronchial asthma. J Trace Elem Med Biol. 2000;14(2):88-91. doi: 10.1016/S0946-672X(00)80036-X. [PubMed: 10941719].

20. Lautenbacher L, Perzanowski MS. Global asthma burden and poverty in the twenty-first century. Int J Tuberc Lung Dis. 2017;21(11):1093. doi: 10.5588/ijtld.17.0638. [PubMed: 29037288].

21. Reddel HK, Bateman ED, Becker A, Boulet LP, Cruz AA, Drazen JM, et al. A summary of the new GINA strategy: A roadmap to asthma control. Eur Respir J. 2015;46(3):622-39. doi: 10.1183/13993003.00853-2015. [PubMed: 26206872]. [PubMed Central: PMC4554554].

22. World Health Organization. Iron deficiency anemia. Assessment, prevention, and control: A guide for programme managers. WHO;2001.15 p.

23. Stevens GA, Finucane MM, De-Regil LM, Paciorek CJ, Flaxman SR, Branca F, et al. Global, regional, and national trends in haemoglobin concentration and prevalence of total and severe anaemia in children and pregnant and non-pregnant women for 1995-2011: A systematic analysis of population-representative data. Lancet Glob Health. 2013;1(1):e16-25. doi: 10.1016/S2214-109X(13)70001-9. [PubMed: 25103581]. [PubMed Central: PMC4547326].

24. World Health Organization. Worldwide prevalence of anaemia 19932005. Geneva, Switzerland: WHO; 2008.

25. Ghasemi A, Ataei Nakhaei A, Alizadeh Ghamsari A, Salehi M, KalaniMoghaddam F. Anemia, iron deficiency anemia and lead poisoning in children with opioid toxicity: A study in North East of Iran. Iran J Pediatr Hematol Oncol. 2017;7(2):90-7.

26. Sayyari AA, Sheikhol-Eslam R, Abdollahi Z. Prevalence of anaemia in 2-12-year-old Iranian children. East Mediterr Health J. 2006;12(6):8048. [PubMed: 17333826].

27. Akbari M, Moosazadeh M, Tabrizi R, Khatibi SR, Khodadost M, Heydari ST, et al. Estimation of iron deficiency anemia in Iranian children and adolescents: A systematic review and meta-analysis. Hematology. 2017;22(4):231-9. doi: 10.1080/10245332.2016.1240933. [PubMed: 27741938].

28. Eftekharzadeh-Mashhadi I, Hedayati-Moghaddam MR, Fathimoghadam F, Bidkhori HR, Shamsian SK. Anemia as a public health issue in Mashhad, Iran: Evidence from the first population-based study. Acta Med Iran. 2015;53(3):186-90. [PubMed: 25796027].

29. Adamu AL, Crampin A, Kayuni N, Amberbir A, Koole O, Phiri A, et al. Prevalence and risk factors for anemia severity and type in Malawian men and women: Urban and rural differences. Popul Health
Metr. 2017;15(1):12. doi: 10.1186/s12963-017-0128-2. [PubMed: 28356159]. [PubMed Central: PMC5371260].

30. Kim JY, Shin S, Han K, Lee KC, Kim JH, Choi YS, et al. Relationship between socioeconomic status and anemia prevalence in adolescent girls based on the fourth and fifth Korea National Health and Nutrition Examination Surveys. Eur J Clin Nutr. 2014;68(2):253-8. doi: 10.1038/ejcn.2013.241. [PubMed: 24300911].

31. Gompakis N, Economou M, Tsantali C, Kouloulias V, Keramida M, Athanasiou-Metaxa M. The effect of dietary habits and socioeconomic status on the prevalence of iron deficiency in children of northern Greece. Acta Haematol. 2007;117(4):200-4. doi: 10.1159/000098273. [PubMed: 17199080].

32. Clark KM, Li M, Zhu B, Liang F, Shao J, Zhang Y, et al. Breastfeeding, mixed, or formula feeding at 9 months of age and the prevalence of iron deficiency and iron deficiency anemia in two cohorts of infants in China.JPediatr. 2017;181:56-61. doi: 10.1016/j.jpeds.2016.10.041. [PubMed: 27836288]. [PubMed Central: PMC5274569].

33. Dell S, To T. Breastfeeding and asthma in young children: Findings from a population-based study. Arch Pediatr Adolesc Med. 2001;155(11):1261-5. doi: 10.1001/archpedi.155.11.1261. [PubMed: 11695937].

34. Lodge CJ, Tan DJ, Lau MX, Dai X, Tham R, Lowe AJ, et al. Breastfeeding and asthma and allergies: A systematic review and meta-analysis. Acta Paediatr. 2015;104(467):38-53. doi: 10.1111/apa.13132. [PubMed: 26192405].

35. Bener A, Ehlayel MS, Hamid Q. The impact of anemia and hemoglobin level as a risk factor for asthma and allergic diseases. Indian J Allergy Asthma Immunol. 2015;29(2):72. doi:10.4103/0972-6691.178271.

36. Eissa SA, Mohammad AA, Ibrahim SA, Abd-Elgwad ER, Soliman NSAE. Iron deficiency anemia as a risk factor in childhood asthma. Egypt J Chest Dis Tuberculosis. 2016;65(4):733-7. doi: 10.1016/j.ejcdt.2016.05.004.

37. Triche EW, Lundsberg LS, Wickner PG, Belanger K, Leaderer BP, Bracken MB. Association of maternal anemia with increased wheeze and asthma in children. Ann Allergy Asthma Immunol. 2011;106(2):131139 e1. doi: 10.1016/j.anai.2010.11.007. [PubMed: 21277514]. [PubMed Central: РMC3073499].

38. Quaye IK. Extracellular hemoglobin: The case of a friend turned foe. Front Physiol. 2015;6:96. doi: 10.3389/fphys.2015.00096. [PubMed: 25941490]. [PubMed Central: PMC4403290].

39. Kassebaum NJ, Jasrasaria R, Naghavi M, Wulf SK, Johns N, Lozano R, et al. A systematic analysis of global anemia burden from 1990 to 2010 . Blood.2014;123(5):615-24. doi:10.1182/blood-2013-06-508325. [PubMed: 24297872]. [PubMed Central: PMC3907750].

40. Brigham EP, McCormack MC, Takemoto CM, Matsui EC. Iron status is associated with asthma and lung function in US women. PLoS One. 2015;10(2). e0117545. doi: 10.1371/journal.pone.0117545. [PubMed: 25689633]. [PubMed Central: PMC4331366].

41. Moayeri H, Bidad K, Zadhoush S, Gholami N, Anari S. Increasing prevalence of iron deficiency in overweight and obese children and adolescents (Tehran Adolescent Obesity Study). Eur J Pediatr. 2006;165(11):813-4. doi: 10.1007/s00431-006-0178-0. [PubMed: 16733667]. 